\title{
Geothermal energy application in Campi Flegrei Area: The case study of a swimming pool building
}

\author{
Martina Barbato ${ }^{1}$, Luca Cirillo ${ }^{1}$, Luigi Menditto ${ }^{1}$, Roberto Moretti ${ }^{1}$, Sergio Nardini ${ }^{1,2^{*}}$ \\ ${ }^{1}$ Dipartimento di Ingegneria Industriale dell'Informazione, Università degli Studi della Campania \\ "Luigi Vanvitelli", Via Roma 29, 81031 Aversa (CE), Italy \\ ${ }^{2}$ Sun Energy Europe S.R.1., Academic Spin-Off, Via B. De Capua 26, 81043 Capua (CE), Italy
}

Email: sergio.nardini@unicampania.it

\begin{abstract}
Swimming pool is an important direct use application of low and medium temperature geothermal fluids. Campi Flegrei area is a location particularly advantageous for a geothermal plant installation at either low or medium temperature. Below the depth where ground temperature is dependent on ambient one, temperature gradient is typically equal to $0.03 \mathrm{~K} / \mathrm{m}$, but at Campi Flegrei it is much larger. With the exception of hottest areas, characterized by steaming ground, thermal springs and fumarolic emissions, a good value is about $0.2 \mathrm{~K} / \mathrm{m}$. In this paper, the design of a geothermal energy plant for air conditioning and heating of water in swimming pool building will be discussed. The building occupies a surface of $2185 \mathrm{~m}^{2}$ of area and the swimming pool is $25.0 \mathrm{~m}$ long, $17.0 \mathrm{~m}$ wide and it has an average depth of $1.80 \mathrm{~m}$. Building thermal loads are evaluated by means TRNSYS ${ }^{\circ}$. Energy requirement for water heating is evaluated taking into account heat losses from pool surface and for water evaporation. The geothermal system is designed taking into account the geological and hydrogeological characteristics of the site, the characteristics of the geothermal plant and energy conversion system. Finally, a cost analysis will be also presented.
\end{abstract}

Keywords: Geothermal Energy, Renewable Energy, Life Cycle Energy Analysis, Swimming Pool, Heat Pump.

\section{INTRODUCTION}

Swimming pools one of the most popular types of sports facility and are used for Olympian races, diving, water polo and recreation. They include dressing rooms with shower facilities, training rooms, managerial offices, storage spaces, mechanical rooms, general use office spaces for meetings, etc., secondary training areas, medical rooms.

The action plan for sustainable development, Agenda 21, adopted in the "Rio's Earth Summit 1992" has been regarded as a key factor in driving swimming pools and other business to recognize the important of environmental management.

Geothermal energy is a source of energy stored in form of heat in the earth's crust and is considered always available as well as inexhaustible [1-3]. Part of this heat derives from the slow cooling from primordial heat, involved Earth's formation, and part derives from the decay of long-living radioactive isotopes by crustal rock minerals. The hottest areas of the Earth's surface are near tectonic plate boundaries, which are often associated also with volcanoes and seismic activity and where hot magmatic bodies are present. The heat flow at the Earth's surface, therefore, derives from the radiogenic decay within the upper crust, the heat generated in the most recent magmatic episode, and the heat coming from the mantle and inner Earth's structures. In the direct use, geothermal energy is employed directly as heat without further conversion into other types of energy. Direct use of geothermal heat and water dates back thousands of years and it continuous today. The Romans, Chinese, and Native Americans left clear proofs that they used geothermal water for heating, cooking and for therapeutic purposes. Where accessible, natural hot waters have been used for space heating in cold areas and seasons. Today geothermal water is used for many different applications depending on the temperature of the water, including electricity generation, which is the most important form of utilization of high-temperature geothermal resources $\left(>120^{\circ}\right)$. Heat demand represents a significant share of final energy consumption for space heating, especially in cold countries, agricultural and industrial processes. Geothermal heat production systems may meet the demand simply providing fluids at the required temperature. Geothermal resources, as opposed to hydrocarbon ones, are generally renewable since the circulation of heat and fluid is continuous. There is a constant terrestrial heat flow to the surface, then to the atmosphere from the immense heat stored within the Earth, and fluid enters reservoir from the recharge zones or injected in the subsurface through injection wells (in industrial plants). Heat can be extracted at different rates. To guarantee a sustainable use of geothermal energy, the rate of consumption should not exceed the rate of generation, so that the heat 
removed from the resource is replaced on a comparable time scale. Geothermal plants typically develop below a certain level of energy production. Geothermal typically provides base-load generation, since it generally immune from weather and seasonal variation, therefore producing almost constantly and distinguishing it from several other renewable technologies that produce variable power or heat with time. Manzella [4] described all possible applications of geothermal technologies that use the heat contained in the ground. In the ground source heat pumps (GSHP) the refrigerant fluid exchanges heat with the ground, taking advantage of the fact that the ground has a constant temperature throughout the year and it is technology for the direct use of heat.

Demirbas et al. [5] described the potential of geothermal energy in the Kingdom of Saudi Arabia. Their results show advantages and disadvantages of geothermal energy in KSA. Heating of swimming pools constitutes an energy consumable procedure. The continuously rising fossil prices increased the swimming pools' heating cost. This fact, combined with the economic crisis, most of the swimming pools in Southern Europe are obligated to close. The high energy consumption in swimming pools presents an attractive challenge and significant opportunities for energy conversion and improved indoor conditions [6-11]. Typically, in swimming pools, the energy consumption is made up of $45 \%$ for ventilation of the pool hall, $33 \%$ for pool water heating, $10 \%$ for heating and ventilation systems for the remainder of the building, $9 \%$ electricity for power equipment and lighting and 3\% for hot water services [12]. Many studies about heating of swimming pools using alternative passive or active heating technologies have been studied in previous articles.

In the work of Katsaprakakis [13] is shown the comparison of swimming pools alternative passive and active heating system based on renewable energy sources in Southern Europe. He studied systems both technically and economically versus fundamental criteria. His results show that the swimming pool's heating cost can be reduced drastically with renewable energy sources active system. Besides his results estimated that the payback periods can be lower than 5 years. Ribeiro et al. [14] studied an approach to optimized control of HVAC systems in indoor swimming pools. The development of the control model is based on the environmental control variables determination that optimize the energy efficiency index (EEI) and the HVAC system contributes to the energy cost (ECs). They believe that the great advantage of this type of control is related to the possibility of completely calibrating it according to the updates in electricity and gas prices.

Lam and Chan [15] carried out a cost analysis of heat pump application for hotel swimming pools. The energy requirement for maintaining the pool water temperature is analyzed in terms of the energy loss through namely evaporation, radiation, convection and water refill. A life cycle of 10 years is used to calculated the net present value (NPV) of the energy cost. They have demonstrated that there is a reduction of HK\$ 275700 considering a system with a heat pump, instead of a conventional electric boiler or condensing boiler.

Currently, there is very little information on the energy performance of geothermal plants and financial implications. Such data are important in deciding whether to adopt geothermal technology for new swimming pools or existing ones during a major refurbishment. The primary aim of this study is, therefore, to appraise the energy savings potential of geothermal technology applications for swimming pools. Besides, the aim of this paper is also to design a geothermal system for a Municipal pool. The study is composed of three parts: identification of the physic model; define the heating and cooling loads of the pool by using TRNSYS Simulation Studio; design the geothermal system considering the particular site (active volcanic area); economic analysis to define the payback time.

\section{PRINCIPLES AND METHODS}

\subsection{Swimming pool thermal loads}

In this analysis, a geothermal system at low-medium enthalpy for a swimming pool in Southern of Italy is designed. The sports complex is of $2185 \mathrm{~m}^{2}$, it is divided into 5 functional areas:

- $\quad$ entrance area, dressing rooms and services;

- $\quad$ pool of $17 \times 25 \mathrm{~m}^{2}$, variable depth between 1.20 and $1.80 \mathrm{~m}$

- $\quad$ plant area at ground floor;

- $\quad$ multipurpose area at foreground;

- $\quad$ solarium and relax area.

The building reference is only the swimming pool because it is built apart to other areas.

The model is defined and implemented taking into account several variables: climate, specifically location and country (Table 1), and with respect of all the requirements. In accordance with the Comitato Olimpico Nazionale Italiano (CONI), regulations for sports facilities approved by the CONI National Council Resolution no. 1379 of June 25, 2008, and with the 16.01.2003 agreement between the Health Ministry, the Regions and the Autonomous Provinces of Trento and Bolzano, as well as with International Swimming Federation (FINA) regulations for 2009/2013 systems, the features of a swimming pool have to be:

- $\quad$ Ambient air temperature, $\mathrm{T}_{\mathrm{amb}}=25^{\circ} \mathrm{C}$;

- $\quad$ Lighting, 300 lux;

- $\quad$ Ventilation, $30 \mathrm{~m}^{3} / \mathrm{h}$;

- $\quad$ Air exchange, $9000 \mathrm{~m}^{3} / \mathrm{h}$;

- $\quad$ Air max velocity, $0.10 \mathrm{~m} / \mathrm{s}$;

- $\quad$ Pool water temperature, $\mathrm{T}_{\mathrm{w}}=26^{\circ} \mathrm{C}$;

- $\quad$ Relative humidity, $\phi \leq 68 \%$;

- $\quad$ Maximum noise level, $40 \mathrm{dBA}$

Table 1. Climate data

\begin{tabular}{cc}
\hline Variable & Value \\
\hline Site & Agnano - Italy \\
\hline Altitude & $74 \mathrm{~s} .1$. \\
\hline Latitude & $40.8539^{\circ}$ \\
\hline Degree days & 1269 \\
\hline Climate zone & $\mathrm{C}$ \\
\hline Distance by the sea & $<40 \mathrm{~km}$ \\
\hline Average wind speed & $2.3 \mathrm{~m} / \mathrm{s}$ \\
\hline Winter external air temperature, $\mathrm{t}_{\text {air,w }}$ & $+2{ }^{\circ} \mathrm{C}$ \\
\hline Heating season & 15 November $-31 \mathrm{March}$ \\
\hline Summer external air temperature, & $+32{ }^{\circ} \mathrm{C}$ \\
\hline tair,h & $45 \%$ \\
\hline External relative humidity &
\end{tabular}


The features of the opaque and transparent elements of the structure are very important to guarantee the environmental requirements into swimming pool. The building is characterized by a precast concrete (sandwich panel) and ribbon windows shaded by projecting concrete elements. Windows cover $38 \%$ of the exterior vertical surfaces, are double glazed (inside argon) with an aluminum frame with high thermal performances. U-values of the structure components are evaluated by inspection and typical construction types of the time.

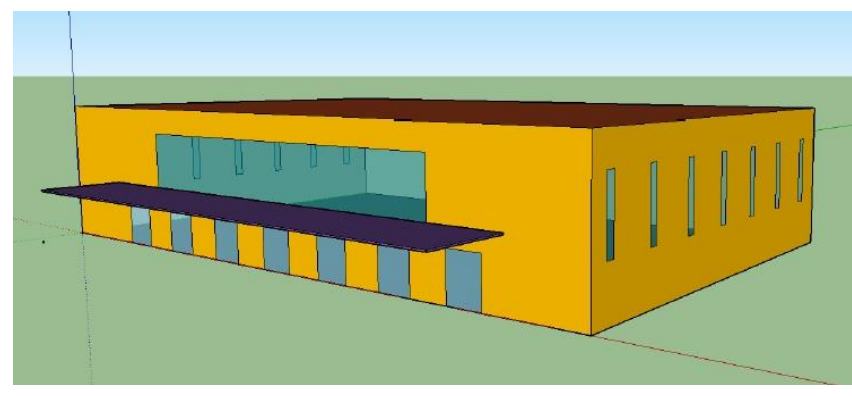

Figure 1. Swimming pool model

\subsection{Transmission loads-TRNSYS model}

Dynamic simulation is exploited in order to get reliable results: using TRNSYS ${ }^{\odot}$ simulation program and Meteonorm climatic data file.

A numerical model is created on the basis of design drawings and inspections. Building construction characteristic together with shading elements, boundary conditions, internal gains, heating set points and schedules are assigned according to real conditions. Given the proportional relation between heating consumptions and external temperatures, a target consumptions profile is created proportionally to the degreedays of the climatic data file.

Figure 2 shows the annual transmission loads profile. It is possible to observe that the heating demand is greater than cooling demand because it is necessary to maintain constant at $25^{\circ} \mathrm{C}$ the ambient temperature for whatever value of the external temperature.

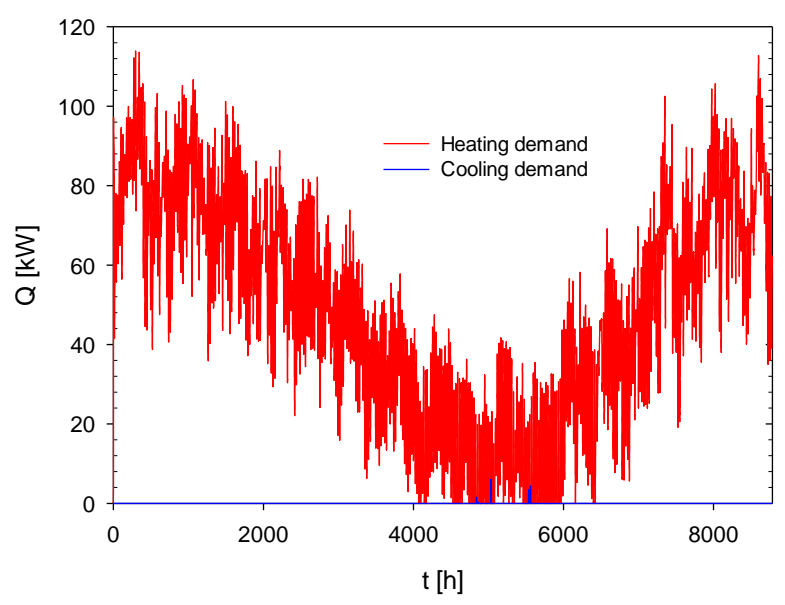

Figure 2. Annual transmission loads profile

The monthly energy demand is shown in Figure 3. It shows the maximum value of the energy demand in winter is in January and December because it is in this month that there is a greater need for heating; the maximum value of the summer energy demand is obtained in July.

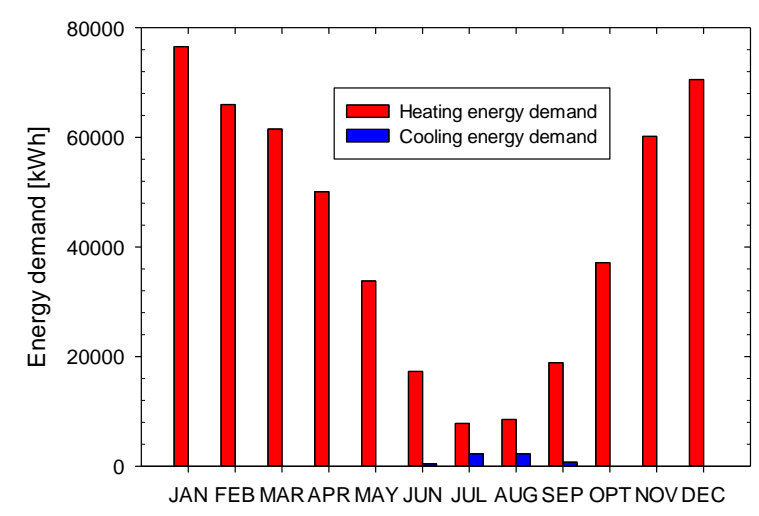

Figure 3. Monthly energy demand taking into account transmission loads

\subsection{Energy demand for pool water and the sizing of the geothermal plant}

The required energy must guarantee the working temperature of the pool, which has a volume of $892.5 \mathrm{~m}^{3}$. Here, we present only the case of continuous $(24 \mathrm{~h})$ working of the plant, with the pool constantly kept at $26^{\circ} \mathrm{C}$, which is the most convenient to take advantage of the whole thermal exchange with the underground heat reservoir. From water enthalpy balances, Figure 4 shows the pool energy demand, also including heat dispersion to the ambient, evaporation loads and the screening effect of the building, limiting heat dispersion.

The total yearly energy demand is thus estimated to be 508 $\mathrm{MWh}$, whose less than $1 \%(3.69 \mathrm{MWh})$ is needed to heat the pool in the cold season in light of its important volume (Figure 4).

On this basis, it is possible to size the geothermal plant in relation to the thermogeological features of the site of interest and the plant technology and set-up.

The site of interest is located within the Campi Flegrei, a volcanic area in the Naples surroundings. There, geothermal gradient is high because of the presence of boiling aquifers and the ascent of steam-rich hot fluids [16-17]. A good value for the geothermal gradient is $17^{\circ} \mathrm{C} / 100 \mathrm{~m}[17,19]$, observed at several drilling sites, including Agnano, which also allows neglecting any consideration about the depth of the neutral thermal layer. Moreover, it allows exploiting the potential for medium-enthalpy geothermal exploitation using a combined geothermal pump/power generator based on utilizing Organic Rankine Cycle (ORC). We considered using a "green machine" Electra Therm (model 6500 Stand Alone). This supplies 50 $\mathrm{kW}$ for liquid water at $90^{\circ} \mathrm{C}$ pumped in at $22 \mathrm{l} / \mathrm{s}$ to the heat exchanger. Nevertheless, in order to by-pass issues about extraction and re-injection, we have evaluated the possibility of directly exchanging heat downhole, setting-up a much safer closed-loop circuit. Typically, such a configuration is adopted for borefields in low-enthalpy geothermal applications.

Our calculations were based on an iterative-ASHRAE procedure [20] accounting for subsoil features, pump technical features and energy demands. Drift effects, dispersion terms and the best thermal coupling by borehole filling material (improved bentonite) were accounted for in order to provide the equivalent amount of heat for electricity co-generation. An 
improved method was presented in [21, 22]. The proposed procedure demonstrated to be very accurate for borehole heat exchanger (BHE) design since it allows a reliable but easy estimation of the Temperature penalty within a calculation frame that mimics the formulas of the original ASHRAE method in order to maintain its simplicity. Table 2 lists the reservoir input data adopted for the procedure.

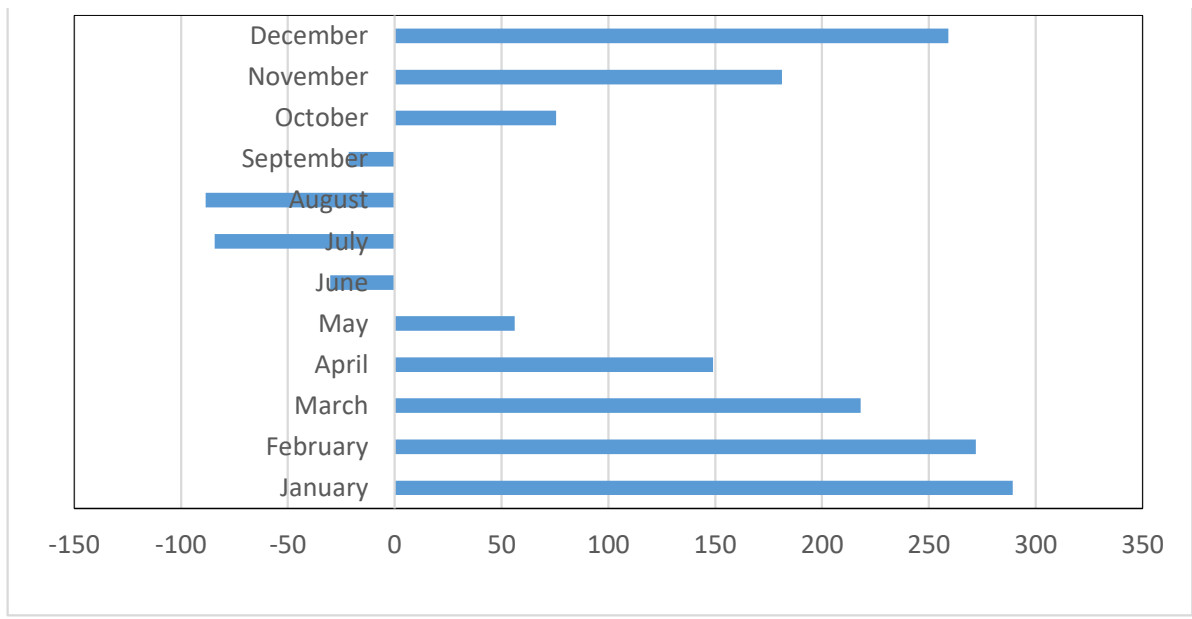

Figure 4. Monthly energy demand [kWh] for pool heating to $26^{\circ} \mathrm{C}$ in case of continuous working

Table 2. ASHRAE method input data

\begin{tabular}{cc}
\hline Thermal conductivity $\mathrm{k}(\mathrm{W} / \mathrm{mK})$ & $9.61 \mathrm{E}-01$ \\
\hline Thermal diffusivity $\alpha\left(\mathrm{m}^{2} / \mathrm{s}\right)$ & $7.30 \mathrm{E}-07$ \\
\hline Subsoil density $\rho\left(\mathrm{kg} / \mathrm{m}^{3}\right)$ & 1795.54 \\
\hline Heat capacity c $(\mathrm{J} / \mathrm{kgK})$ & $7.33 \mathrm{E}+02$ \\
\hline Bottom Hole $\mathrm{Thh}\left({ }^{\circ} \mathrm{C}\right)$ & 120 \\
\hline $\begin{array}{c}\text { Power exchanged by the linear probe in } \\
\text { winter q }(\mathrm{W} / \mathrm{m})\end{array}$ & 193.66 \\
\hline
\end{tabular}

For the considered conditions, it is possible to obtain the desired machine performance with one single drilling, completed by a vertical probe $400 \mathrm{~m}$ long. As a further consideration, we say that implementing geothermal in the area could also produce positive feedbacks for improving our knowledge of subsoil features, highly needed for geohazard assessments of the area [23].

\subsection{Financial analysis}

In order to evaluate the economic feasibility of the geothermal plant, an economic analysis is carried out on the configuration taking into account both capital and operating costs of the system.

To carry out the economic analysis, and thus to evaluate the investment in the case examined, it is necessary to consider the length of the probes, the unit cost of the land-side heat exchanger (probe), then the total cost of the probe, and the initial cost, which includes the cost of heat pump, as well as the costs necessary for drilling.

In this analysis, the considered costs are:

- Drilling costs

- Cost for probing

- Cost for the electrical plant for the energy production, and therefore of the heat pump to co-generate electricity

- Cost of connection to the electricity network

Investment analysis is carried out by analyzing the cash flows; in addition to cash flows that are produced by the new investment, it is also considered the time factor, in the economic - financial sense.
Drilling costs are $60 €$ for meter, while probing costs are $50 €$ for meters and the cost of the heat pump is equal to $15000 €$, besides, it is necessary to consider the cost of the connection to electricity network and workmen:

$$
\begin{aligned}
& C_{\text {plant }}=C_{D}+C_{P}+C_{H P} \\
& C_{\text {conn }}=0.15 C_{\text {plant }} \\
& C_{W}=84000 € \\
& C_{\text {tot }}=C_{D}+C_{P}+C_{H P}+C_{c o n n}+C_{W}
\end{aligned}
$$

where $C_{D}$ are drilling costs, $C_{P}$ is the probes cost, $C_{H P}$ is the heat pump cost, $\mathrm{C}_{\text {conn }}$ is the connection cost, $\mathrm{C}_{\mathrm{W}}$ is the workmen cost. The total initial investment is summarized in table 3. To assess the economic feasibility of the plant, it should be made an estimate of the annual cost savings, cash flows accumulated, the payback time. The following table shows some financial data, including the annual savings in euro, achieved thanks to the construction of the plant; Furthermore, it is essential to consider the annual maintenance and electricity consumption related to the electric pumps and control devices.

Table 3. Investment

\begin{tabular}{ccc}
\hline $\mathrm{C}_{\mathrm{D}}$ & 240000.00 & $€$ \\
$\mathrm{C}_{\mathrm{P}}$ & 200000.00 & $€$ \\
$\mathrm{C}_{\mathrm{HP}}$ & 15000.00 & $€$ \\
$\mathrm{C}_{\text {conn }}$ & 88500.00 & $€$ \\
$\mathrm{C}_{\mathrm{W}}$ & $2 \times 42000.00$ & $€$ \\
$\mathrm{C}_{\text {tot }}$ & $\mathbf{6 2 7 5 0 0 . 0 0}$ & $€$ \\
\hline
\end{tabular}

Legislatively in Italy, there are incentives for the production of energy from renewable sources. The duration of the incentive in years is a function of the type of intervention; in the present case, the duration is five years. The annual savings in euro has been assessed as the difference between the cost of primary energy before the installation of 
the plant and after implantation: this value of $28900 €$ is the cost savings achieved at the end of the first year of investment, then, considering the fuel inflation rate, it is estimated the actual cost savings, year by year.

Table 4. Economic parameters

\begin{tabular}{ccc}
\hline Initial cost & 627500.00 & $€$ \\
Incentive & 407875.00 & $€$ \\
Energy cost before GS & 85600.00 & $€ /$ year \\
Energy cost after GS & 56700.00 & $€ /$ year \\
Annual money savings & 28900.00 & $€ /$ year \\
Annual maintenance & 13250.00 & $€ /$ year \\
General inflation rate & 2.00 & $\%$ \\
\hline
\end{tabular}

Table 5. Parameters related economic financial analysis

\begin{tabular}{ccc}
\hline NPV (Net Present Value) & $€ 136.776,64$ & $€ 259.245,43$ \\
IRR (Internal Rate return) & $6,1 \%$ & $7,4 \%$ \\
PBT (Pay Back Time) & 10,5 & 10,5 \\
\hline
\end{tabular}

The payback period was calculated as the ratio between the initial investment and the cash flows; clearly, the lower the value of the payback, the lower the investment risk since it would require less time to recover the money invested. NPV and IRR are calculated: NPV represents the profit generated by the investment, expressed in money; IRR is the return offered by the project, calculated on the initial outlay on the basis of cash flows in future periods.

The values reported in Table 5 are referred to an analysis conducted for twenty and twenty-five years. Figure 14 shows the payback period is 15.4 years and the NPV increases linearly with the years.

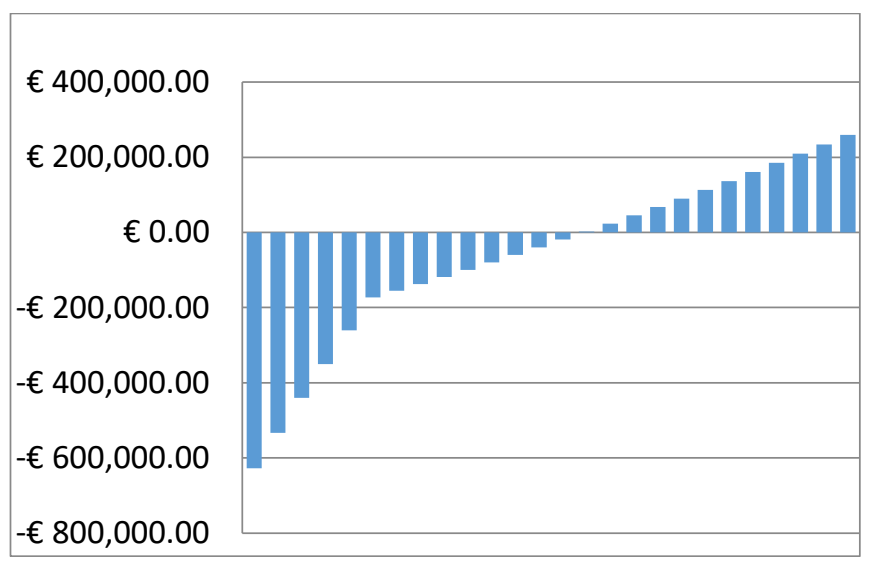

Figure 14. NPV estimated to twenty-five years

\section{CONCLUSIONS}

An integrated analysis of thermal loads and energy demand of a swimming pool and its associated facility has been carried out. In spite of the very accurate TRNSYS elaboration of heat loads and losses, it is shown that the most energy demanding contribution is due to the pool heating during the cold season. The possibility of adopting geothermal, including co-generation electricity, was then considered in light of the high geothermal gradient of the area (Campi Flegrei). Our results testify for the feasibility of such a solution, which should then be implemented in the whole "hot" area of Campi Flegrei (highly urbanized and inhabited) as a form of diffuse energy co-generation. In fact, produced electricity could be either stored or delivered for distribution, providing additional benefits to producers and the community. Rather than extracting hot water and pump it to the heat exchanger, we also evaluated the possibility of downhole heat exchange by configuring a closed-loop geothermal circuit, usually adopted in low-enthalpy applications. A major advantage of this would be the low environmental impact (no groundwater extraction and re-injection), opening new perspectives in the area for the diffusion of geothermal, at present somehow limited by policies about groundwaters and relative administrative issues. The analysis shows that the whole setup is economically convenient, with a payback time of 10.5 years given present fiscal incentives and rules, only if the system operates $24 \mathrm{~h}$ uninterruptedly. This is however in line with the long-life of the considered machine under working conditions.

\section{REFERENCES}

[1] Di Pippo R. (1980). Geothermal energy as a source of electricity: A worldwide survey of design and operation of geothermal power plants, US Government Printing Office, Washington DC.

[2] Di Pippo R. (2004). Second low assessment of binary plants generating power from low temperature geothermal fluids, Geothermics, Vol. 33, pp. 565-86.

[3] Selek M.A., Murathan A., Demirbas A. (2008). Electricity production from geothermal sources by using double stage flash system, Energy Sources Part A, Vol. 30, pp. 1884-89.

[4] Manzella A. (2015). Geothermal energy, EPJ Web of Conferences, Vol. 98, No. 04004. DOI: 10.1051/epjconf/20159804004

[5] Demirbas A., Alidrisi H., Ahmad W., Sheikh M.H. (2016). Potential of geothermal energy in the Kingdom of Saudi Arabia, Energy Sources, Part A: Recovery, Utilization, and Environmental Effects, Vol. 38, No. 15, pp. 2238-43. DOI: 10.1080/15567036.2015.1045999

[6] Lazzarin R.M., Longo G.A. (1996). Comparison of heat recovery systems in public indoor swimming pools, App. Thermal Eng., Vol. 16, No. 7, pp. 561-70.

[7] Johansson L., Westerlund L. (2001). Energy savings in indoor swimming-pools: comparison between different heat-recovery systems, App. Energy, Vol. 70, pp. 281303.

[8] Lazzarin R.M. (1992). Alternative heating of a municipal swimming pool, Int. J. Refrig., Vol. 6, pp. 118-22.

[9] Lazzarin R.M., Longo G.A. (1992). Open cycle absorption-a simple route to gas-fired cooling and heating, IEA Heat Pump Newsletter, Vol. 10, pp. 12-15.

[10] Lazzarin R.M., Longo G.A. (1992). An open cycle absorption heat pump, Heat Recovery Systems \& CHP, Vol. 12, pp. 391-96.

[11] Stourna E.T., Spyropoulou K., Theofylakros C., Droutsa K., Balaras C.A., Santamouris M., Asimakopoulos D.N., Lazaropoulou G., Papanikolaou N. (1998). Energy conservation strategies for sports centres: Part B Swimming pools, Energy and Buildings, Vol. 27, pp. 12535.

[12] Energy efficiency in buildings, sports centers, Energy Efficiency Office, Department of the Environment, London. 
[13] Katsaprakakis D.A. (2015). Comparison of swimming pools alternative passive and active heating systems based on renewable energy sources in Southern Europe, Energy, Vol. 81, pp. 738-53. DOI: 10.1016/j.energy.2015.01.019

[14] Ribeiro E.M.A., Jorge H.M.M., Quintela D.A.A. (2016). An approach to optimised control of HVAC systems in indoor swimming pools, Int. J. of Sust. Energy, Vol. 35, No. 4, pp. 378-95. DOI: 10.1080/14786451.2014.907293

[15] Lam J.C., Chan W.W. (2001). Life cycle energy cost analysis of heat pump application for hotel swimming pools, Energy Conv. And Manag., Vol. 42, pp. 1299-306.

[16] Caliro S., Chiodini G., Moretti R., Avino R., Granieri D., Russo M., Fiebig J. (2007). The origin of the fumaroles of La Solfatara (Campi Flegrei, south Italy), Geochimica et Cosmochimica Acta, Vol. 71, No. 12, pp. 3040-3055.

[17] Carlino S., Somma R., Troise C., De Natale G. (2012). The geothermal exploration of Campanian volcanoes: Historical review and future development, Renewable and Sustainable Energy Reviews, Vol. 16, No. 1, pp. 10041030.

[18] Fedele A., Pedone M., Moretti R., Wiersberg T., Somma R., Troise C., De Natale G. (2017). Real-time quadrupole mass spectrometry of hydrothermal gases from the unstable Pisciarelli fumaroles (Campi Flegrei): Trends, challenges and processes, International Journal of Mass Spectrometry.

[19] Di Renzo V., Wohletz K., Civetta L., Moretti R., Orsi G., Gasparini P. (2016). The thermal regime of the Campi Flegrei magmatic system reconstructed through 3D numerical simulations, Journal of Volcanology and Geothermal Research, Vol. 328, pp. 210-221.

[20] Philippe M., Bernier M.A., Marchio D. (2010). Sizing calculation spreadsheet for verticalgeothermal borefields, Ashrae Journal, pp. 20-28.

[21] Fossa M., Rolando D. (2015). Improving the Ashrae method for vertical geothermal borefield design, Energy and Buildings, Vol. 93, pp. 315-32.

[22] Fossa M., Rolando D. (2016). Improved Ashrae method for BHE field design at 10-year horizon, Energy and Buildings, Vol. 116, pp. 114-121.

[23] De Natale G., Troise C., Mark D., Mormone A., Piochi M., Di Vito M.A., Somma R. (YEAR). The Campi Flegrei Deep Drilling Project (CFDDP): New insight on caldera structure, evolution and hazard implications for the Naples area (Southern Italy), Geochemistry, Geophysics, Geosystems.

\section{NOMENCLATURE}

$\mathrm{T}$

$\mathrm{k}$

c

q

C

IRR

PBT

\section{Greek symbols}

$\sqrt{ }$

$\alpha$

$\rho$

\section{Subscripts}

$\mathrm{amb}$

w

bh

D

$\mathrm{P}$

HP

W

conn
Temperature $\left({ }^{\circ} \mathrm{C}\right)$

Thermal conductivity $(\mathrm{W} / \mathrm{m} \mathrm{K})$

Heat capacity $(\mathrm{J} / \mathrm{kgK})$

Linea Power exchanged $(\mathrm{W} / \mathrm{m})$

Cost $(€)$

Net present value $(€)$

Internal rate return $(€)$

Payback time (year)

Humidity

Thermal diffusivity $\left(\mathrm{m}^{2} / \mathrm{s}\right)$

Density $\left(\mathrm{kg} / \mathrm{m}^{3}\right)$

Ambient condition
Water
Bottom hole
Drilling
Prob
Heat pump
Workmen
Connection at electricity network

